\title{
Saving the Greater Adjutant Stork by Changing Perceptions and Linking to Assamese Traditions in India
}

\author{
Purnima Devi Barman ${ }^{1 *}$, D. K. Sharma ${ }^{2}$, John F. Cockrem ${ }^{3}$, Mamani Malakar ${ }^{1}$, Bibekananda Kakati ${ }^{1}$, and Tracy Melvin ${ }^{4}$ \\ ${ }^{1}$ Aaranyak, Guwahati, Assam, India. ${ }^{2}$ University of Science and Technology Meghalaya, Baridua, India. ${ }^{3}$ School of Veterinary \\ Science, Massey University, Palmerston North, New Zealand. ${ }^{4}$ Department of Fisheries and Wildlife, Michigan State \\ University, East Lansing, USA. \\ *purnima.aaranyak@gmail.com
}

\begin{abstract}
The Greater Adjutant Stork (Leptoptilos dubius), locally known as Hargila (the bone swallower) is an endangered bird with an estimated global population of less than 1200. Habitat loss, poisoning, and poaching have caused large declines in populations of this stork in South Asia, with the Brahmaputra valley in Assam in northeastern India now the last stronghold for the species. The stork nests colonially in privately owned trees within thickly populated villages. Tree owners would cut down trees to prevent rotten food and excreta of this carnivorous bird from falling into their backyards. A change in attitudes of the nest-tree owners towards keeping their trees and towards Greater Adjutants has been the key to stork conservation. A conservation project involving community development, education and outreach, interlinking storks with local traditions and cultures, and capacity building of local communities was initiated in 2007. A rural women's conservation group named the Hargila Army was instituted and strong feelings of pride and ownership for the storks by the villagers have been generated. Cash incentives for nest protection were deliberately avoided, with schemes that indirectly contribute to the livelihoods of nest-tree owners and other villagers introduced instead. The success of the conservation program is shown by the increase in the number of nesting colonies in the village area of Dadara, Pachariya, and Singimari in Kamrup District in Assam from 28 nests in 2007-08 to 208 nests in the 2019-20 breeding season, making this the largest breeding colony of Greater Adjutant Storks in the world.
\end{abstract}

Received September 9, 2019

OPEN ӘACCESS

Accepted April 7, 2020

Published December 4, 2020

DOI 10.14237/ebl.11.2.2020.1648

Keywords Women's Leadership, Conservation Programs, Community Development, Ethno-ornithology

Copyright (c) 2020 by the author(s) licensee Society of Ethnobiology. This is an open-access article distributed under the terms of the Creative Commons Attribution-NonCommercial 4.0 International Public License (https://creativecommons.org/licenses/by-nc/4.0), which permits non-commercial use, distribution, and reproduction in any medium, provided the original author and source are credited.

\section{Introduction}

The Greater Adjutant Stork (Leptoptilos dubius; see Figure 1) is the second rarest stork species in the world and is classified in the IUCN Red List as endangered (BirdLife International 2016). The species has a ranking in the top 100 of 9895 species of birds for Evolutionarily Distinct and Globally Endangered (EDGE) scores (Jetz et al. 2014). The Greater Adjutant was previously widely distributed from Pakistan through northern India, Nepal, and Bangladesh to Myanmar, Thailand, Laos, Vietnam, and Cambodia (Birdlife International 2001). The population has been estimated to be many hundreds of thousands in the late 1800s (BirdLife International 2001); however, there was a dramatic decline during the first half of the 20th century, and in the early 1990s it was thought that the population was around 400 birds (Perennou et al. 1994). Reasons for the decline of the Greater Adjutant population include habitat destruction, felling of nest-trees, drainage and pollution of wetlands, poaching, and environmental contaminants (BirdLife International 2019). Greater Adjutant Storks are now found only in Assam and Bihar in India (Choudhary et al. 2011; Mandal and Saikia 2013), and in Cambodia (Campbell et al. 2006). The total population was assessed in 2008 to be 800 to 1200 mature individuals (approximately 1200 to 1800 birds in total), with a decreasing population trend (BirdLife International 2019). The current population is likely to be less than $1 \%$ of the population of 100 years ago. 


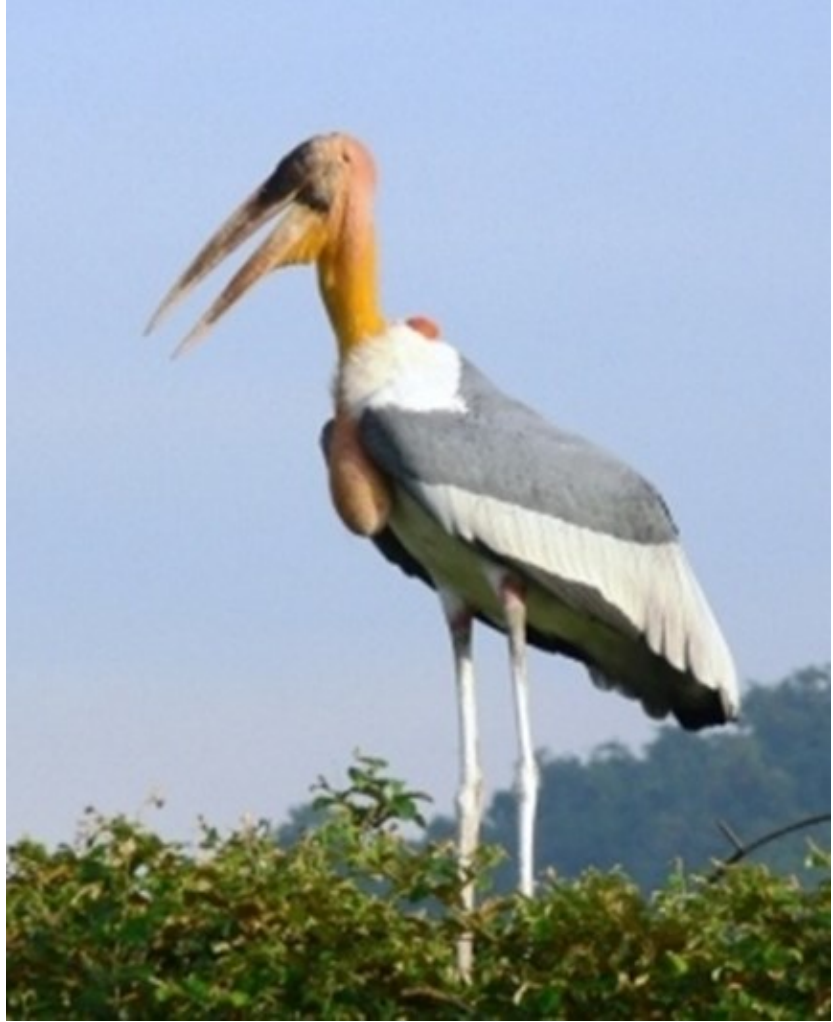

Figure 1 Greater Adjutant Stork in Assam. Photograph by Rathin Barman.

Knowledge of breeding sites of Greater Adjutants in India was limited to 75 sites found during a survey conducted in 1989 and 1990 in Assam (Saikia and Bhattacharjee 1990a, 1990b). The largest colony had 31 nests, with most of the nests in private forest areas in villages and suburban areas. Threats to the species were identified as the killing of storks, felling of nesting trees for wood or to remove storks due to dislike of the noise and smell of nests with young birds, lack of awareness of the species and its status as legally protected, and the loss of wetland foraging habitat (Saikia and Bhattacharjee 1990b).

A survey of Greater Adjutants conducted in both breeding and nonbreeding seasons from 1994 to 1996 found 573 storks in the Brahmaputra Valley of Assam in the breeding season. Almost $75 \%$ of the Assam population was in the Kamrup District, primarily near the city of Guwahati (Singha et al. 2003). The birds bred in privately owned trees, preferring trees in thickly populated villages. The largest breeding colonies of Greater Adjutants were in the DadaraPachariya-Singimari villages of the Kamrup District. A survey by the first author and a team in 2007 and 2008 found only 40 nests and 430 birds in all of
Assam.

Greater Adjutants build nests in tall trees on private land in the home gardens of villagers. The trees were most commonly Neolamarckia cadamba, Bombax ceiba, Artocarpus lacocha, Artocarpus beterophylu, Pithecellobium monadelphu, and Archidendron bigeminum (Barman 2018). Nesting trees could be located very close to houses, with up to 15 nests in one tree. Adult birds bring fish, snakes, waste meat, and bones to their nests to feed the chicks. These food items often fall on the ground along with fecal matter of the birds, so the area underneath the nesting sites often has a foul smell. Chicks can fall from the flimsy nests and dead chicks underneath the nests make the area unpleasant. The owners of nest trees often used to disturb the birds to make them leave. Nest-tree owners would also fell the nesting trees to earn extra money to support their families, especially during marriages of their daughters and sons. Many of the nest-tree owners believed that conservation of the bird was the responsibility of a government forest department and the government should pay the owners if they allowed the storks to make nests in their private trees.

This article describes the development of community support for conservation of the Greater Adjutant Stork in the nesting colony in the DadaraPachariya-Singimari village areas of the Kamrup District in Assam. The conservation efforts were initiated in 2007. Before then the villagers, particularly the tree owners, did not know that the Greater Adjutant is an endangered bird and that nests in their villages were important for the survival of the storks. The villagers responded to the initiation of the conservation program and became involved in the protection of the trees and in activities to promote the conservation of the storks. This has resulted in a three-fold increase in the number of successful nests in the colony since the conservation program began.

\section{Study Area}

The authors initiated a holistic community conservation program in 2007 in the DadaraPachariya-Singimari villages of the Kamrup District of Assam. Dadara, Singimari, and Pachariya $\left(26^{\circ} 13.31^{\prime} 9^{\prime \prime}\right.$ $\mathrm{N}$ and $\left.91^{\circ} 37.58^{\prime} 6^{\prime \prime} \mathrm{E}\right)$ are three adjoining small villages approximately $12 \mathrm{~km}$ from Guwahati city (see Figure 2). These villages are situated near Poondoba beel, Digholi beel, and Jeng beel (beel means wetland in Assam). The Brahmaputra River is about four kilometers from these villages while the Deepor Beel, a 

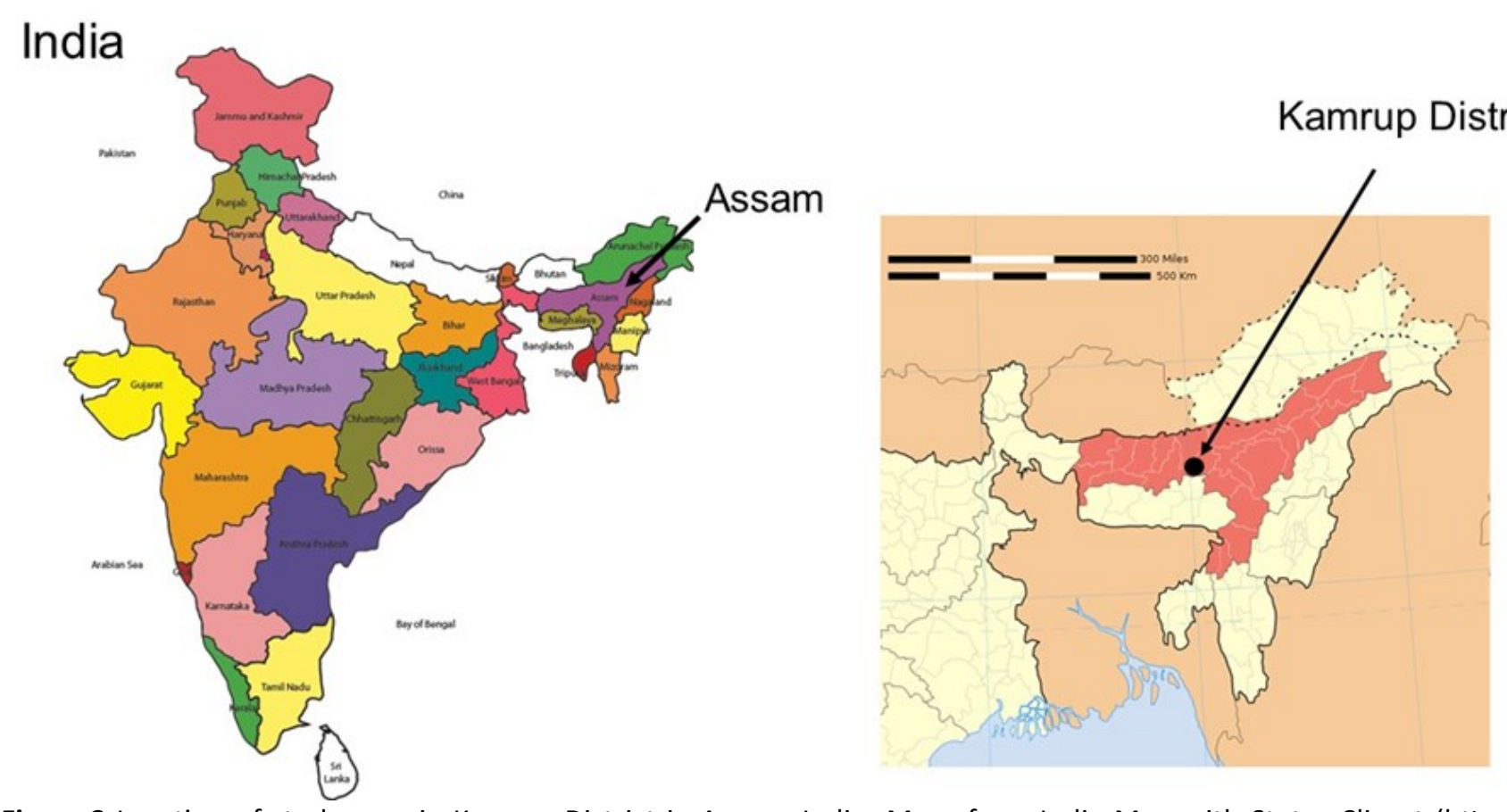

Figure 2 Location of study area in Kamrup District in Assam, India. Maps from India Map with States Clipart (https:// www.clipart.email/clipart/india-map-with-states-clipart-232537.html) and Creative Commons by PlaneMad/Wikimedia (https://commons.wikimedia.org/wiki/File:India_Assam_locator_map.svg).

wildlife sanctuary and internationally recognized waterbird site, is about eight kilometers away. The Guwahati garbage dump, a feeding area for Greater Adjutants in the non-breeding season, is about $14 \mathrm{~km}$ from the villages. The climate of the area is humid mesothermal Brahmaputra with hot, wet summers. Reported minimum and maximum temperatures are $7^{\circ} \mathrm{C}$ and $38.5^{\circ} \mathrm{C}$. The annual rainfall in the district ranges from 1500 to $2200 \mathrm{~mm}$.

\section{Overview of Conservation Program}

We started with a pre-campaign survey in DadaraPachariya-Singimari villages to understand the motivations of the nest-tree owners. The survey results indicated that the villagers were not aware of the importance of the endangered Greater Adjutant. In many cultures around the world birds are considered to provide omens of the future (Hull and Fergus 2017; Wyndham and Park 2018). The stork was treated by the villagers as a bad omen because it feeds on the carcasses of animals and brings bones and debris to its nesting trees. People cut down the nest building trees due to the messy habits of the birds and to clear the land for house expansion. They were also not fully aware of the importance of wildlife conservation in their daily lives. Various community conservation activities were designed to motivate nest-tree owners based on the survey results. We identified various key groups in the villages who could influence the nest-tree owners to allow Greater Adjutants to make nests in their private trees. We approached young students, women, and respected elderly persons from the locality to generate an "ownership feeling" amongst the villagers for having Greater Adjutants in their villages.

A rural women's group named the Hargila Army was instituted to empower the women and to expand their voices to protect the storks. Livelihood tools (approaches that help people gain capabilities to financially sustain their households) were introduced to these women and regular biodiversity classes were organized to empower and enlighten the women. As a result, 10,000 rural women have pledged to be involved in the Hargila Army and to be voices for unprotected areas. Baby showers for stork chicks were regularly organized to encourage the women. Looms and yarn were distributed and opportunities for the women to enroll in a Diploma in Fashion Technology were provided. These women were engaged in 
weaving traditional Assamese garments called gamosas, with stork motifs incorporated into the traditional decorations. The Hargila campaign was integrated with the holy book Bhagawat Gita procession, a local festival of the community.

A conservation campaign was planned involving students, villagers, celebrities, media personalities, and policy makers. Regular education workshops were arranged in local schools and community sites to raise the awareness of the villagers and school children living in the vicinity of the breeding colony. Meetings were organized between policy makers and local people to understand the local situation for conservation of the bird. Information sheets were published in local languages to spread the message of conservation of the stork and were distributed freely to local people, school libraries, and community places. Street plays were performed in the vicinity of the breeding colonies to portray the situation of this bird and the need for its conservation.

It is not uncommon for chicks to fall out of nests. Nylon nets were placed under the nesting colonies to catch fallen chicks. Chicks that fell into the nets were taken to the Assam State Zoo for rehabilitation and hand rearing. Chicks that survived were released back into the wild. Events were organized when chicks were released so that the conservation needs of the storks could be highlighted. Released birds were named after local school children and after renowned conservationists and tree owners' children. Some releases were also celebrated by symbolically naming the birds after women from tree-owning families. Seventy-eight chicks have been released.

Policy makers were enlisted into the program when conducting major field events such as bird releases. A baby shower program for Greater Adjutants during the breeding season was initiated, an in-kind donations program with awards to nest-tree owners' children for excelling in examinations was begun, and Wetland Day celebrations and Earth Day celebrations were held.

A process to formulate a species recovery plan for the Greater Adjutant was initiated. This was done through a series of workshops where government policy makers were invited along with experts in this field. During these meetings, government decision makers were informed about the facts and figures of this species and made aware of the urgent need for its conservation. The first author donated money which she received from the President of India for her Nari
Shakti Purashkar award (the highest civilian award for Indian women) to the women of the villages. She has also donated money from several other awards and has donated personal resources to the village women which has led to increased awareness of their responsibilities for conservation of the storks.

\section{Work with Women}

Greater Adjutant Storks in Assam nest in trees that are often in backyard gardens of village houses. The storks were disliked as they were considered to be unclean due to their habits of feeding on garbage and on waste from the slaughter of animals including cows. The birds drop partially eaten animal food and fecal matter into the gardens, thereby creating extra work for village women to keep their gardens clean. A focus of the conservation program for the storks has been to work with women in the villages. Village women were initially shy and reluctant to participate in conservation discussions, so programs were organized specifically for the women. We played a "web of life" string game with them to help them understand the importance of each species in their surroundings. We organized cooking, crafts, and folk music competitions for the women who were not comfortable with participating in discussions. A cooking competition held during the Assamese bibu festival provided an opportunity for women to spontaneously participate in discussions about conservation of Greater Adjutants in their own villages. During the discussion, they were amazed to know that this endangered bird had chosen only their villages in which to breed. This knowledge led them to decide that they would not allow any disturbances during the breeding season of this bird. They even celebrated and publicly made wishes to the birds for a successful nesting season in their villages in the same way as they celebrate the first pregnancies of their own female relatives.

The Hargila Army, Economic Help for Women, and Traditional Linkage through Weaving

We formed a rural women's group called the Hargila Army to help empower women to conserve Greater Adjutants whilst at the same time helping them with their economic livelihoods. The women were primarily from families that own trees with nests, and all had expert weaving skills. We provided weaving looms, yarn, and sewing machines so that the women could create textiles decorated with traditional Assamese motifs. Training at a local Fashion Institute 
was arranged for village women. The gamosa is a traditional Assamese scarf which is another reflection of Assam culture and this gamosa is highly respected and loved by Assamese people. Gamosas are made with stork motifs by the Hargila Army women of the nesting colony. They were very proud to make these gamosas, which were not only sold as tools of livelihoods but also presented to guests, government officials, experts, and media personnel who visited the nesting colony as gestures from the villagers. A communal weaving center was established in 2017 after the project received a Whitley Award (also called a Green Oscar) so the women could come and weave together. An internship training program on weaving was also designed so that rural women could learn weaving and get certificates. Eighty sewing machines were distributed in 2019 and this facility became stronger. This facility trained and benefited around 1,050 women from the village including women from adjacent areas. The Hargila army is a group that not only works for the Hargila but is also a voice of women for saving rural and backyard biodiversity in unprotected areas where the government does not have influence.

We received requests from villagers to be paid to conserve storks nesting in their village. We consciously avoided offering cash to the nest-tree owners to support the stork nesting colonies. This decision was made as the sustainability of cash offers would be very difficult and this might create bigger problems for the bird in the future. Instead, we have provided new economic opportunities for the women so their financial livelihood can be linked with their involvement with conservation.

\section{Work with School Students and Young People}

At the very beginning of the conservation program we created environmental education activities for local school students. Rather than going from one school to another, we concentrated on a small private school (Sankardeva Sisu Niketan) located at the heart of the nesting colony villages. The majority of the pupils at this school were children of nest-tree owners. We introduced the students to the importance of biodiversity and wildlife conservation through play and group activities. Children were involved through spot drawing competitions and after each competition a presentation was made to them describing the importance of this bird. Quizzes and poetry competitions for the students were also held in order to involve the students in conservation of the
Greater Adjutant in their villages. Regular environmental education activities with the students of this school gradually introduced them to the Greater Adjutant. They all were surprised to know that they lived with an endangered bird in their home gardens. As the program developed, local schools were designated as guardians of the storks. Apart from these programs, educational materials (posters and leaflets) were published and freely distributed among the local students. Work in the first 12 years of the conservation program has educated 12,000 school children in learning about nature, bird watching, and other activities to increase their awareness of the natural environment. We introduced a small scholarship program for local students who secured good marks in board examinations. Local students were the beneficiaries and almost all of them were children of nest-tree owners.

We organized many group meetings with youth in their twenties. The young people were informed about the importance of the Greater Adjutant, and it was specifically mentioned that if they successfully conserved this nesting colony, their village could be a destination for bird tourism. A few bird tourism groups were introduced to these young people who served as guides in birding trips to the nesting colony. Young people were also taken to the Assam State Zoo to introduce them to other conservation initiatives.

In the nesting colony many young chicks die after falling out of their nests (Barman, 2018). Although this is a natural process, saving chicks that fall from nests will help the population of an endangered bird. Once the groups of young people knew about the importance of this bird, they rescued many nest-fall chicks and handed them over to the Assam State Zoo for further treatment and rehabilitation. The young people did not previously have any concern for these nest-fall birds which would otherwise have died. Released birds were named after young students so that the motivation for conservation of this bird would be taken to another level.

\section{Work with Local Police}

It is always important to have on board law enforcing authorities while implementing any community conservation program in India. We engaged with the local police as stakeholders for conservation of this globally endangered bird. The Kamrup Police Department was invited to participate in the conservation efforts for storks in the local nesting colony. Police Department staff actively participated 


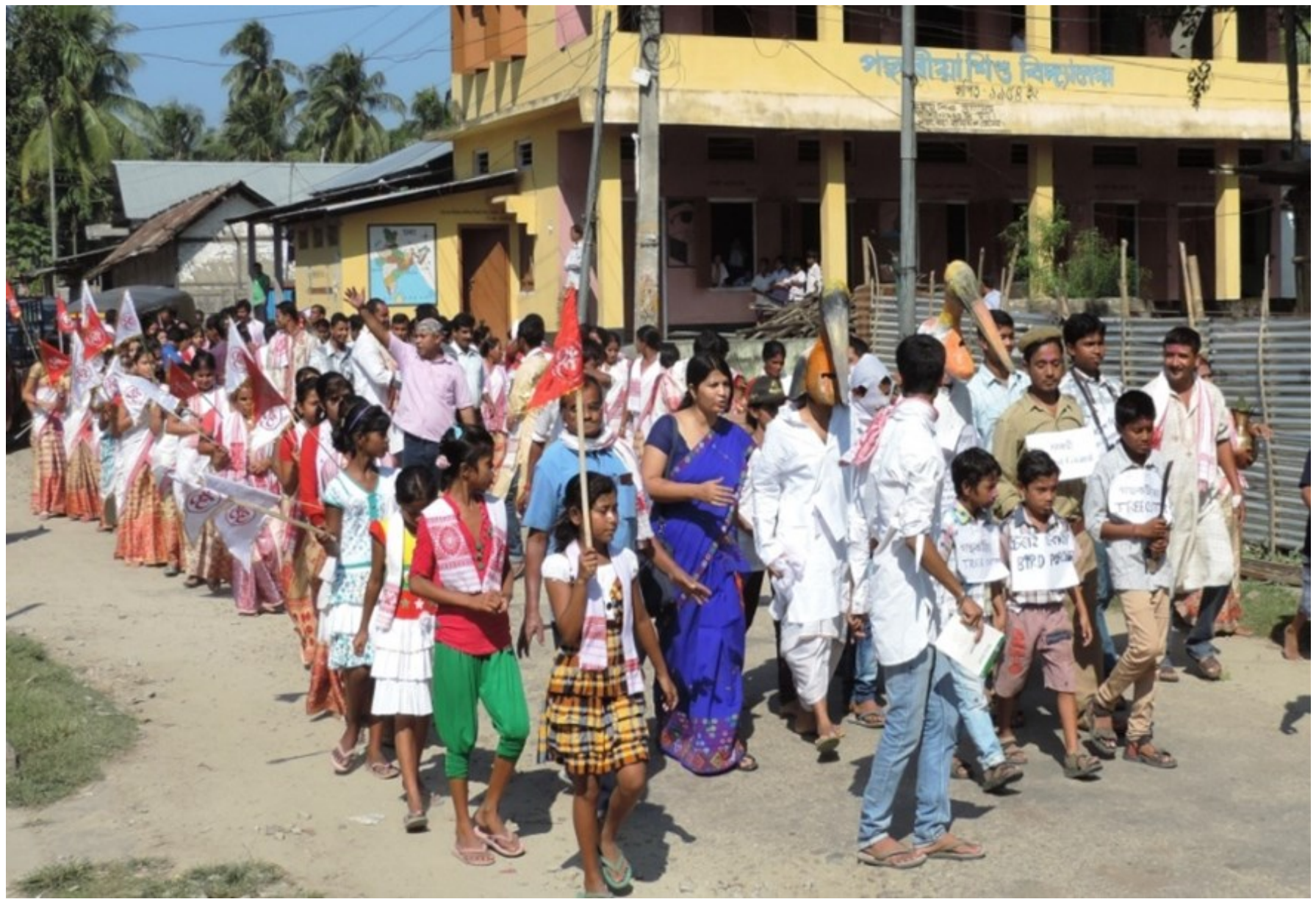

Figure 3 A cultural procession for stork conservation. Photograph by Rathin Barman.

in conservation program activities and even voluntarily published a roadside sign with conservation messages about the storks in the area. The involvement of police made a real difference and poachers did not have the courage to disturb or kill storks in the colony.

\section{Integration with Local Religious Events}

The story about storks helping in the delivery of human babies was narrated to the local elderly women. They liked the story and decided to include storks in the local religious procession (Figure 3). This motivated people greatly and they publicly supported the conservation efforts for this stork in their area.

When we started conservation work in 2007, villagers complained about the birds and cut down nesting trees of storks. After some years of active community engagement, the villages have taken ownership of the species and are proud to live with the Hargila. Incorporation of the conservation campaign into the villagers' ritual belief system has played a large part in the effort to protect the species. Tree and animal species are symbols of Gods and Goddesses in Indian culture (Bhatt 2010), and mythology and ritual beliefs can be a major tool for enhancing conservation awareness. The Greater Adjutant is called Garuda (the bird vehicle of Lord Vishnu) in Bihar mythology and people treat this bird as God. We used this mythology to motivate the women's group. In 2015 an awareness program was held during Janmashtami (the birth Festival of Lord Shri Krishna) with women of Dadara village. The women were motivated to write Naam songs (prayer songs) with Hargila conservation messages and to perform street drama to motivate others. Village womenfolk prayed to God for a better life for their bird called Hargila who comes to their villages for breeding year after year. Village women composed new prayer songs, for example "Hargila, you are safe in our village. Come and breed here and grow your family. 
We are blessed with your presence in our villages".

\section{Publicity}

Media organizations are briefed periodically about the importance of the Greater Adjutant through many formal and informal meetings. The media play a very positive role and keep publishing information about the conservation program so the general public are made aware of the program activities. Outcomes from the publicity include sharing information about the storks with people from very remote areas. Publicity has included the preparation of a poster in the local vernacular language. The poster highlighted the importance of the bird and appealed for its conservation. The poster was distributed freely to villagers, students, and community groups in the areas with stork colonies and has been very popular. A leaflet with similar messages was also prepared and presented to government officials.

A campaign using social media with a Facebook group page "Greater Adjutant network" has been part of the conservation program. Many participants have subscribed to this web page and valuable information and suggestions have been gathered through Facebook. The group enables the exchange of information for conservation of the Greater Adjutant in Assam. Some participants in the page have volunteered during a survey of the status of Greater Adjutants throughout Assam and have even participated in various campaign field activities.

\section{Involvement of a Local Celebrity}

A popular Assamese film actress, Ms. Prastuti Parasar, was invited to visit the nesting colony. She was asked to interact with the local people to encourage the conservation of this bird. Local people were overwhelmed by the presence of this celebrity in their own villages, sitting with them and having tea with them. The message from the celebrity had a deep impact, especially in young people. They promised the celebrity to support the endangered Greater Adjutant in their villages.

The celebrity publicly felicitated all the nest-tree owners and photo sessions were arranged for the nest-tree owners with the celebrity. Felicitation is a Hindu practice to honor someone as a mark of respect by wrapping a shawl around their shoulders. The visit to the nest sites in the villages by the popular Assamese film actress was an instant hit and was found to be very effective for spreading the conservation message. The villagers said that because of the storks the film celebrity visited their villages and they felt proud of that.

\section{Success of the Conservation Program}

When the first author visited this nesting colony in 2007-08, there were 28 nests and trees were being cut down in this colony and in other adjacent colonies in Assam. She started the conservation campaign and with support from local communities tried to ban the hunting of storks which was done by outsider tribal groups. These groups hunted storks for food and there were reports that stork meat was sometimes sold in restaurants as chicken meat. As a result of the continuous conservation efforts not a single tree has been cut down since 2010 and nest numbers have increased. Communities have banned the hunting and killing of this species which was often done by a group of tribal people coming from other villages. The Hargila Army now has 400 women as tree protectors. Four hundred women and their families have received benefits for their livelihoods, and 1,050 rural women have benefitted from schemes to learn new skills. Furthermore, 12,000 school children received nature learning opportunities and bird watching training as future conservators. Nest numbers at the nesting colony increased eight-fold from 28 nests in 2007 to 208 in 2020 and the Kamrup District colony is now the largest Greater Adjutant colony in Asia. Nests numbers in Assam state have increased from 40 to 270 nests over 12 years. We conducted a survey of Greater Adjutant Storks in 2020 and found 950 birds in Assam.

Communities responded to the conservation program and stopped felling nesting trees in Dadara Pacahriya village, with no trees cut down since 2010. In 2007 six trees were cut down, in 2008 six big nesting trees were cut down, and in 2009 four nesting trees were cut down, so slowly people stopped cutting down the trees. The stork population has continued to grow (Figure 4), and in the 2019-2020 breeding season there were 208 successful nests in this breeding colony. There are about 650 storks in the district in which the colony is located and the colony is the largest known Greater Adjutant nesting colony. The number of storks at a garbage dumping site near Guwahati city, the main feeding ground for the storks in the nonbreeding season, has also increased since the conservation program began. The current population of storks is approximately $50 \%$ greater than reported after a survey conducted in the breeding season in 1994-1995 and in the nonbreeding season 


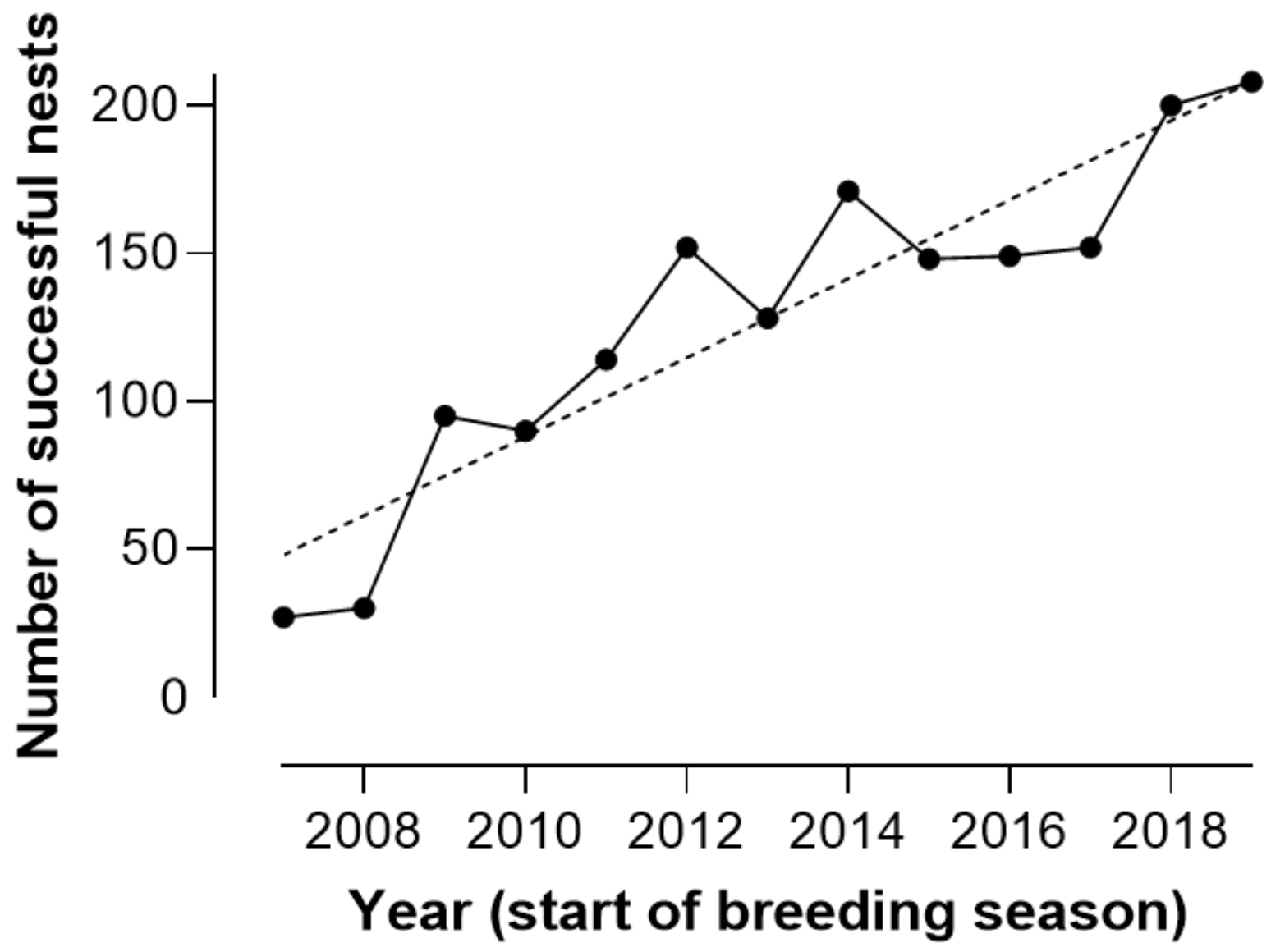

Figure 4 Number of successful Greater Adjutant Stork nests in Dadara, Pasariya, and Singimari villages in Assam. The dashed line shows a linear regression $\left(y=13.3 x+34.6, r^{2}=0.853, p<0.0001\right.$; linear regression conducted using Prism [GraphPad Software, La Jolla, CA]), indicating that the increase in the number of nests since 2007 is statistically significant.

in 1996 (Singha et al. 2003). Each year the colony is recruiting into the breeding population an average of 75 birds that had previously fledged from the colony as chicks. Furthermore, 85 young birds that had fallen from nests have been rescued and released so far. Support from the community and the work of the conservation program led to recognition of these villages by Birdlife International as Important Bird Areas (IBA site IN-AS-49 Dadara-PachariyaSingimari) (Rahmani et al. 2016). However, rapid urbanization and unplanned city developments which are expanding to these villages will pose a major threat to this species and its wetland habitats.

\section{Conclusion}

Our program has focused on involvement of the community through persistent and creative approaches to changing people's attitudes towards the storks and developing feelings of ownership of the birds. Involvement of village women has been crucial, including the provision of economic help for their livelihoods. Integration of Hargila conservation into local festivals and belief systems, and work with school students and young people have also been important for the success of the program. This model of community conservation has been included in the school curriculum in India.

Villagers of the Kamrup District nesting colony became an example for community conservation of Greater Adjutants in other districts in Assam. Conservation groups should visit villages in other districts regularly to make the conservation effort ongoing. Community based organizations need to be involved to sustain conservation activities for this 
endangered bird in all nesting colonies in Assam. Bird tourism in these villages might help towards conservation of this species but this needs to be carried out with the active participation of local people and should not be operated for the sole benefit of tour operators. The bird was once hated by local people due to its association with slaughterhouse wastes (against the local religious sentiment), but now the same group of people feels that they are the owners of this bird in their locality. They even symbolically took the birds into their village religious ceremonies. Also, in addition to continuing the program the Government should carry out a proper planning process so that the Greater Adjutants and other species which breed in non-protected areas are not adversely affected by unplanned development.

Our program is a striking example of working with local knowledge and beliefs and incorporating religious events into a successful conservation program for an endangered species of bird. It is rare for ethno-ornithology, the inter-relationships between birds and people that include traditional indigenous knowledge (Tidemann et al. 2010), to be included in avian conservation programs (Bonta 2010). Indeed, the Greater Adjutant Stork program may be the most successful example of such a program. The conservation program for the Hargila can be a practical model for other conservation programs for endangered birds that live and breed in rural districts where the nesting and feeding sites are not in protected areas. The program is also a model of work with local communities to change perceptions of birds perceived as unwanted, for example the endangered Egyptian vulture (Neophron percnopterus) (CortésAvizanda et al. 2018) and the griffon vulture (Gyps fulvus) (Margalida et al. 2014) in Spain. In conclusion, the Greater Adjutant Stork program demonstrates the value of an ethno-ornithological approach to avian conservation in which local people and their beliefs are at the heart of work to halt and reverse the decline of a bird species.

\section{Acknowledgments}

We extend our heartiest thanks to the Conservation Leadership Program, Whitley Fund for Nature, Women in Nature Network, Bombay Natural History Society, New Zealand High Commission, New Delhi, India, Kamrup District Administration, and the Kamrup police for supporting us in conservation initiatives for Greater Adjutants in Assam. We are greatly indebted to Professor Simon Stuart from
Synchronicity Earth, Professor Robert Elner and Professor Robert Butler (27th International Ornithological Congress), Dr. Ashish John from WCS Vietnam, and Dr. Kira Mileham from IUCN for their immense guidance. We are very thankful to Dr. Asad Rahmani of the Bombay Natural History Society, to Mr. B.C. Choudhury, Scientist (Rtd) of the Wildlife Institute of India and to Dr. Bibhab Kumar Talukdar, CEO of Aaranyak, for their support and advice throughout the conservation program. We highly appreciate and acknowledge the Assam Forest Department for their support. We are also highly thankful to the IUCN SSC Stork Ibis Spoonbill group for their support. We highly acknowledge the villagers of Dadara, Pachariya, and Singimari for their constant support. We thank Dr. Nicole Sault for the invitation to contribute to the Avian Voices special issue of this journal, and for her comments on the manuscript.

\section{Declarations}

Permissions: None declared.

Sources of Funding: Funding was received from the Conservation Leadership Program, Whitley Fund for Nature, Women in Nature Network, Bombay Natural History Society and the New Zealand High Commission, New Delhi, India.

Conflicts of Interest: None declared.

\section{References Cited}

Barman, P. D. 2018. Foraging Ecology, Breeding Success and Genetic Status of Greater Adjutant Stork Leptoptilos dubius (Gmelin) in Kamrup District, Assam. Dissertation Thesis, Gauhati University, Guwahati, India.

Bhatt, P. M. 2010. Birds and Nature in the Stepwells of Gujarat, Western India. In Ethno-Ornithology. Birds, Indigenous Peoples, Culture and Society, 1st edition, edited by S. C. Tidemann and A. Gosler, pp. 141151. Taylor and Francis, London.

BirdLife International 2001. Threatened Birds of Asia: The Birdlife International Red Data Book. BirdLife International, Cambridge, United Kingdom.

BirdLife International 2016. Greater Adjutant Leptoptilos dubius. The IUCN Red List of Threatened Species 2016: E.T22697721a93633471. Available at: http://Dx.Doi.Org/10.2305/Iucn.Uk.20163.Rlts.T22697721a93633471.En. Accessed on July 23, 2019.

BirdLife International 2019. Species Factsheet: Leptoptilos dubius. [web page]. Available at: http:// 
Datazone.Birdlife.Org/Species/Factsheet/GreaterAdjutant-Leptoptilos-Dubius. Accessed on January 23, 2019.

Bonta, M. 2010. Ethno-Ornithology and Biological Conservation. In Ethno-Ornithology. Birds, Indigenous Peoples, Culture and Society, 1st edition, edited by S. C. Tidemann and A. Gosler, pp. 13-29. Taylor and Francis, London.

Campbell, I. C., C. Poole, W. Giesen, and J. ValboJorgensen. 2006. Species Diversity and Ecology of Tonle Sap Great Lake, Cambodia. Aquatic Sciences 68:355-373. DOI:10.1007/s00027-006-0855-0.

Choudhary, D. N., J. Mandal, and R. Rohitashwa. 2011. Distribution, and Potential Breeding Records, of Lesser-Leptoptilos javanicus and Greater-L. dubius Adjutant-Stork in Bihar, India. Indian BIRDS $7: 38-40$.

Cortés-Avizanda, A., B. Martín-López, O. Ceballos, and H. M. Pereira. 2018. Stakeholders Perceptions of the Endangered Egyptian Vulture: Insights for Conservation. Biological Conservation 218:173-180. DOI:10.1016/j.biocon.2017.09.028.

Hull, K., and R. Fergus. 2017. Birds as Seers: An Ethno-Ornithological Approach to Omens and Prognostication among the Ch'orti' Maya of Guatemala. Journal of Ethnobiology 37:604-620. DOI:10.2993/0278-0771-38.4.533.

Jetz, W., G. H. Thomas, J. B. Joy, D. W. Redding, K. Hartmann, and A. O. Mooers. 2014. Global Distribution and Conservation of Evolutionary Distinctness in Birds. Current Biology 24:919-930. DOI:10.1016/j.cub.2014.03.011.

Mandal, J., and P. K. Saikia. 2013. Greater Adjutant Storks Leptoptilos dubius Gemlin 1789: Breeding and Foraging Distribution in Kamrup District, Assam, India. European Journal of Zoological Research 2:1-5.

Margalida, A., D. Campion, and J. A. Donazar. 2014. Vultures Vs Livestock: Conservation Relationships in an Emerging Conflict between Humans and Wildlife. Oryx 48:172-176. DOI:10.1017/ s0030605312000889.
Perennou, C., T. Mundkur, D. A. Scott, A. Follestad, and L. Kvenild. 1994. The Asian Waterfowl Census 1987-91: Distribution and Status of Asian Waterfowl. Kuala Lumpur: Asian Wetland Bureau Publication No. 86. International Waterfowl and Wetlands Research Bureau Publication No. 24. Kuala Lumpur, Malaysia and Slimbridge, United Kingdom.

Rahmani, A. R., M. Z. Islam, and R. M. Kasambe. 2016. Important Bird and Biodiversity Areas in India. Priority Sites for Conservation. Second Edition: Revised and Updated. Volume I. Bombay Natural History Society, Indian Bird Conservation Network, Royal Society for the Protection of Birds and BirdLife International (U.K.), Mumbai, India.

Saikia, P., and P. C. Bhattacharjee. 1990a. Discovery of Greater Adjutant Nesting Colonies Outside the Protected Areas of Assam, India. Newsletter for Birdwatchers 30:3.

Saikia, P., and P. C. Bhattacharjee. 1990b. Nesting Records of Greater Adjutant Storks in Assam, India. ICBP/IWWRB/IUCNNR Specialist Group on Storks, Ibises and Spoonbills Newsletter 3:2-3.

Singha, H., A. R. Rahmani, M. C. Coulter, and S. Javed. 2003. Surveys for Greater Adjutant Leptoptilos dubius in the Brahmaputra Valley, Assam, India During 1994-1996. Forktail 19:146-148.

Tidemann, S. C., S. Chirgwin, and J. R. Sinclair. 2010. Indigenous Knowledges, Birds That Have 'Spoken' and Science. In Ethno-Ornithology. Birds, Indigenous Peoples, Culture and Society, 1st edition, edited by S. C. Tidemann and A. Gosler, pp. 3-12. Taylor and Francis, London.

Wyndham, F. S., and K. E. Park. 2018. "Listen Carefully to the Voices of the Birds": A Comparative Review of Birds as Signs. Journal of Ethnobiology 38:533-549. DOI:10.2993/0278-077138.4.533. 